\title{
Sleeves for fixation of Silastic nasolacrimal tubes
}

\author{
B Hopkisson, J Suharwardy
}

\begin{abstract}
Aims-To describe a method of securing indwelling O'Donohughe's lacrimal tubes in dacryocystorhinostomy using two 3-4 mm Watski sleeves

Methods-The operative technique used to secure the sleeves into position on the lacrimal tubes is described. Forty seven procedures with a follow up ranging from 3 to 30 months (mean 10 months) are reviewed.

Results-The tubes and sleeves were well tolerated. Upward prolapse of the tubes occurred only once and the tubes were easily repositioned in this case.

Conclusion-Securing lacrimal tubes with Watski sleeves in dacryocystorhinostomy is a simple, cheap, and effective procedure.
\end{abstract}

(Brf Ophthalmol 1995; 79: 664-666)

Dacryocystorhinostomy and canalicular surgery provide a very high rate of permanent relief of the watery eye, with a failure rate of less than $10 \%$ of cases. ${ }^{1-7}$ To achieve this high rate of success, the insertion of Silastic stents is often required in a number of cases. ${ }^{7-10}$ These tubes have been associated with a variety of minor complications including both upward prolapse and medial 'cheesewiring' of the tubes. The incidence of upward prolapse of the tubes varies between 10-17\% of cases although higher rates have been reported. ${ }^{811-13}$ Various methods for fixing in place, repositioning, or extracting the tubes have been described. ${ }^{9}$ 12-16 The tubes have been fixed simply by knotting the tubing several times, suturing the two lower ends of the tubes together, or anchoring them with silicone strips.

None of these procedures has proved entirely satisfactory. We describe a simple, cheap, quick, and tolerated method of fixing the tubes in the newly created lacrimal drainage system to greatly reduce upward prolapse of indwelling O'Donohughe's tubes.

Northampton General Hospital

B Hopkisson

J Suharwardy

Correspondence to:

Mr B Hopkisson,

Department of

Ophthalmology

Northampton General

Hospital, Northampton

NN1 5BD.

Accepted for publication 14 February 1995

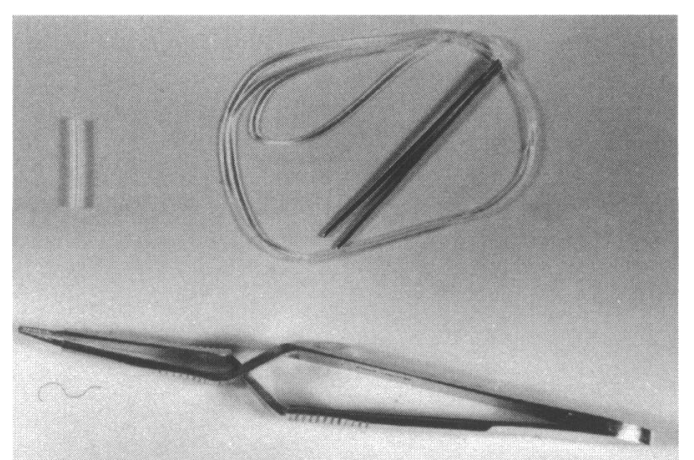

Figure 1 Strip of Watski sleeve with applicator and O'Donohughe's tubes on bodkins.

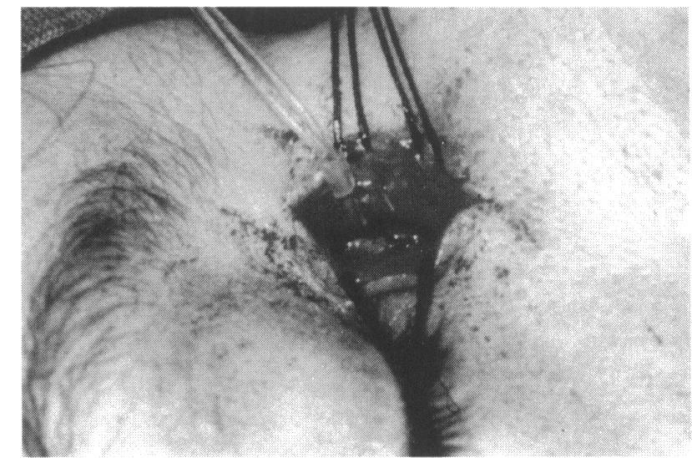

Figure 2 The upper Watski sleeve applied to the tubes at the level of the skin incision plane.

This involves the use of Watski sleeves and the sleeve together with its applicator and the O'Donohughe's tubes on bodkins are shown in Figure 1.

\section{Methods and technique}

We reviewed the notes of all patients who underwent nasolacrimal surgery with indwelling tubes in a $2^{\frac{1}{2}}$ year period from March 1991 to November 1993.

The indications for insertion of tubes were; six cases of mucocele with mucosal folds obscuring the internal ostium, one case of gross traumatic medial canthal scarring, three case of failed previous dacryocystorhinostomy, and 37 cases of common canalicular/internal ostium stenosis.

The surgical technique used is as follows. Routine dacryocystorhinostomy under general anaesthesia, with or without canaliculoplasty as required, is carried out to the point where the osteotomy has been completed and the posterior flaps of nasal and sac mucosa have been sutured. Upper and lower canaliculi together with common canaliculus are intubated with O'Donohughe's tubes on bodkins.

Two 3-4 mm sleeves are cut from a piece of Watski sleeve tubing. The first sleeve is positioned on the Watski sleeve applicator and both upper and lower tubes are passed through the sleeve on the applicator. The tubes are held loosely so that they exit from the wound; the applicator is then released and the sleeve is applied to the tubes at the same level as the skin incision plane (approximately $15 \mathrm{~mm}$ from the inner ostium of the common canaliculus in the sac) (Fig 2). This ensures that the upper sleeve comes to lie just within the nasal cavity and not within the sac when the tubes are finally passed down the nose to exit the nostril. The second sleeve is then applied in an identical manner on the tubes just above the plane of exit from the nostril (Fig 3).

The bodkins are removed; the tubes are then gripped in the bony rhinostomy plane by a pair of artery forceps passed up the nose. The tubes 


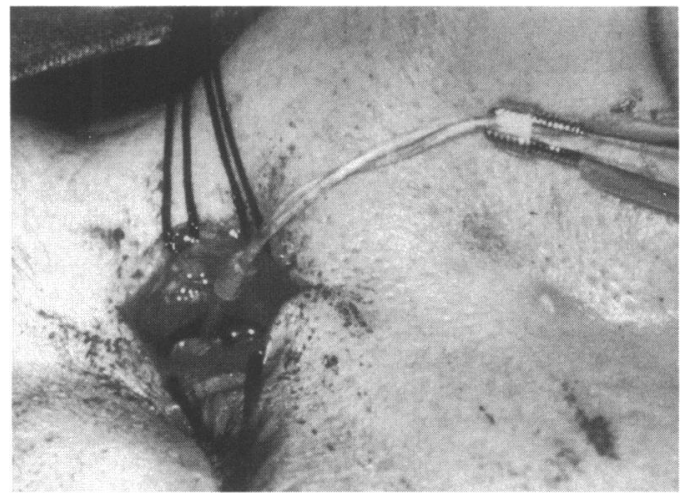

Figure 3 The lower Watski sleeve applied to the tubes just above the plane of exit from the nostril.

are then delivered via the nasal cavity to the nostril and are cut just below the lower sleeve outside the nostril with the tube slightly stretched. On relaxing the stretch, the tubes and lower sleeve withdraw and come to lie within the nasal cavity above the plane of the nostril (Fig 4).

The tubes are left in situ for at least 3 months when they can be removed. They may then be left in place either by choice or if they are not easily removable owing to poor visibility of the lower end of the tubes. We removed the tubes in 34 cases at an interval of 3 to 26 months postoperatively (mean 6.9 months). In eight cases the tubes were left in place and in five cases the patients removed the tubes themselves.

\section{Results}

Forty four patients (23 women and 21 men) had tubes inserted, but one failed to attend postoperatively and so was excluded from the study. Patients' ages ranged from 35 to 86 (mean 59) years and patients were followed up from 3 to 30 (mean 10) months. Forty seven operations were performed on the 43 patients in the study. Three patients had bilateral surgery and one patient required a second operation as the first failed.

There were two cases of postoperative wound infection and one case of postoperative canaliculitis (all treated successfully with antibiotics). There was one postoperative bleed and one case developed mild medial ankyloblepharon which was simply divided with a blade.

Specific complications related to the tubes comprised one case of prolapse temporally from the canthus (easily repositioned per nares) and two cases of medial displacement (cheesewiring) of the tubes into the canthus. These nasal displacements occurred in the case with gross medial canthal trauma (where the tubes had to be replaced in a repeat procedure) and in another case where there had been a previous canaliculoplasty (where they were easily repositioned).

The tubes were removed in 34 cases. In one of these cases the upper sleeve was caught in the bony ostium and remained there, while in eight cases the tubes remain without any problems (longest follow up 30 months).

Of the 45 routine procedures performed,
39 had resolution of their symptoms (87\%), four had a marked improvement (9\%) while two were still under review for potential repeat surgery $(4 \%)$. The case with medial canthal trauma showed a marked improvement after the repeat operation to replace the tubes. The new tubes have caused no problems and remain in place after 20 months of follow up.

\section{Discussion}

An unacceptable rate of upward prolapse of indwelling tubes resulted when they were secured by suturing the lower ends together just above the nostril plane as was our usual practice. This often required the services of ear, nose, and throat colleagues to retrieve and reposition the tubes. The sleeve technique was therefore devised to retain the tubes in the nasal cavity and prevent their upward prolapse.

At first we placed the upper sleeve in the sac just beyond the common canaliculus ostium. This certainly prevented upward prolapse but on attempting to remove the tubes at a later date $30 \%$ (six of 19) of the upper sleeves jammed in the sac at the rhinostomy which had narrowed and the upper sleeve slipped off the tube to remain in the sac. This sleeve retention in the sac has caused no complications to date.

The 47 procedures described here were all carried out placing the upper sleeve within the nasal cavity to prevent jamming and therefore allowing easy removal. In one of these cases the upper sleeve was retained and in one case the tubes did prolapse upwards to a small degree but there was still sufficient tubing in the nose for an ophthalmic surgeon to seize and reposition it via the nostril. Nasal displacement (cheesewiring) with punctal erosion has been reported as a complication of tubes and while this was seen in two cases, it was in those who had had gross trauma or previous surgical procedures on their canaliculi.

The upper sleeve is essential if upward prolapse is to be prevented. The lower sleeve could be left off, but we prefer to have both ends of the tube secured together for ease of removal. The long term placement of tubes has been previously described to be a safe procedure ${ }^{1316}$ and we left tubes in their sleeves in situ in eight patients for up to 30 months with no ill effects.

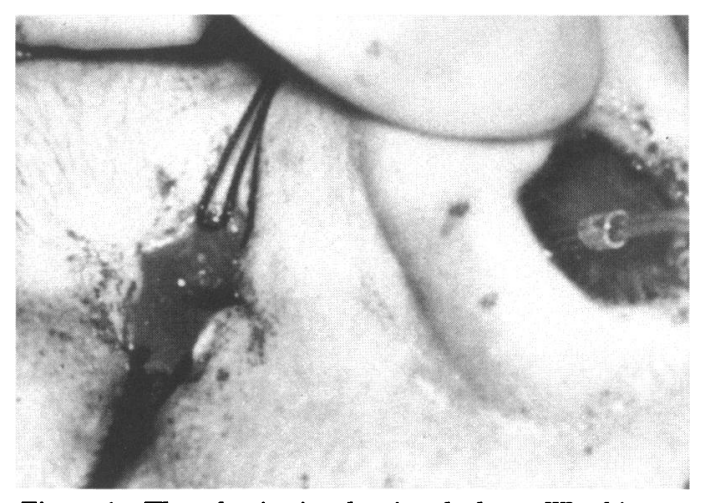

Figure 4 The tubes in situ showing the lower Watski sleeve within the nasal cavity. 
Our surgical results are comparable with other studies and we feel that this method of securing the tubes is a safe, well tolerated procedure which is simple, cheap, and effective.

1 Welham RAN, Wulc AE. Management of unsuccessful lacrimal surgery. $\mathrm{Br} f$ Ophthalmol 1987; 71: 152-7.

2 Jones BR. Principles of lacrimal surgery. Trans Ophthalmol Soc UK 1973; 93: 611-8.

3 Romanes GJ. Dacryocystorhinostomy: clinical report of fifty cases. Br $\mathcal{F}$ Ophthalmol 1955; 39: 237-40.

4 McPherson SD, Egleston D. Dacryocystorhinostomy: a review of 106 operations. Am F Ophthalmol 1959; 72: 328-31.

5 McLachlan DL, Shannon GM, Flanagan JC. Results of dacryocystorhinostomy: analysis of the reoperations. Ophthalmic Surg 1980; 11: 427-30.

6 Hollsten DA. Complications of lacrimal surgery. Int Ophthalmol Clin 1992; 32: 49-66

7 Roper-Hall MJ. Stallards eye surgery. 7th ed. London: Butterworths, 1989: 135-62.

8 Patrinely JR, Anderson RL. A review of lacrimal surgery.
Ophthalmic Plastic and Reconstructive Surgery 1986; 2: $97-102$

9 Older JJ. Routine use of a silicone stent in a dacryocystorhinostomy. Ophthalmic Surg 1982; 13: 911-15.

10 Rosen N, Sharir M, Moverman DC, Rosner $M$ Dacryocystorhinostomy with silicone tubes: evaluation of 253 cases. Ophthalmic Surg 1989; 20: 115-9.

11 Anderson RL, Edwards JJ. Indications, complications and results with silicone stents. Ophthalmology 1979; 86: results with 87 .

12 Dortzbach RK, France TD, Kusner BJ, Gonnering RS Silicone intubation for the obstruction of the naso-lacrima duct in children. Am $f$ Ophthalmol 1982; 94: 585-90.

13 Veloudios A, Harvey JT, Philippon M. Long-term placement of Silastic nasolacrimal tubes. Ophthalmic Surg 1991; 22: 225-7.

14 Beyer RW, Levine MR, Sternberg I. A method for repositioning or extraction of lacrimal system silicone tubes. Ophthalmic Sarg 1986; 17: 496-8.

15 Christmann LM. Crawford tubes - a technique to avoid dislocation. F Pediatr Ophthalmol Strabismus 1991; 28: $290-1$.

16 Lauring L. Silicone intubation of the lacrimal system: pitfalls, problems and complications. Ann Ophthalmol 1976; 8: 489-98. 